\title{
Molecular Diagnosis of Human Metapneumovirus Infection among Egyptian Infants with Acute Bronchiolitis
}

\author{
Gamal El-Din El-Sawaf ${ }^{1}$, Maged Eissa ${ }^{2}$, Abeer Ghazal ${ }^{1}$, Dalia Metwally ${ }^{1}$, \\ Rania Abozahra ${ }^{3}$ and Walid Rafla ${ }^{4}$ \\ ${ }^{1}$ Department of Microbiology, Medical Research Institute, \\ Alexandria University, Alexandria, Egypt \\ ${ }^{2}$ Department of Pediatrics, Faculty of Medicine, Alexandria University, Alexandria, Egypt \\ ${ }^{3}$ Department of Microbiology and Immunology, Faculty of Pharmacy, \\ Damanhour University, Damanhour, Egypt \\ ${ }^{4}$ Department of Microbiology and Biotechnology, Faculty of Science, \\ Alexandria University, Alexandria, Egypt \\ *Corresponding author
}

\begin{tabular}{|c|c|}
\hline & A B S T R A C T \\
\hline & \multirow{10}{*}{$\begin{array}{l}\text { Lower respiratory tract infections are one of the leading causes of morbidity and mortality } \\
\text { in children worldwide. Several viruses can cause bronchiolitis. Respiratory syncytial virus } \\
\text { (RSV), parainfluenza viruses (PIV), influenza type A, adenovirus and human } \\
\text { metapneumovirus (HMPV) are some of the common viruses found in hospital studies. } \\
\text { This study aimed to study the molecular diagnosis of HPMV infections by using a real- } \\
\text { time, reverse-transcriptase PCR assay and the evaluation of its prevalence among Egyptian } \\
\text { infants clinically diagnosed with acute viral bronchiolitis. Also to detect other common } \\
\text { respiratory viruses and determine the presence of coinfections of HPMV and other } \\
\text { respiratory viruses, we tested the presence of common respiratory tract viruses by using } \\
\text { immunofluorescence respiratory screen test in } 50 \text { Egyptian infants diagnosed with acute } \\
\text { bronchitis and also screened the tested samples for the presence of HMPV by using real- } \\
\text { time RT PCR. Our results revealed that } 16 \% \text { of the cases were positive for HMPV, } 76 \% \\
\text { were positive for the other tested common respiratory tract viruses and } 12 \% \text { showed } \\
\text { coinfection. }\end{array}$} \\
\hline & \\
\hline Human & \\
\hline $\begin{array}{l}\text { Metapneumovirus, } \\
\text { Bronchiolitis, RT }\end{array}$ & \\
\hline PCR, Infants. & \\
\hline Article Info & \\
\hline Accepted: & \\
\hline 24 March 2017 & \\
\hline Available Online: & \\
\hline 10 April 2017 & \\
\hline
\end{tabular}

\section{Introduction}

Lower respiratory tract infections are one of the leading causes of morbidity and mortality in children worldwide (Hustedt and Vazquez, 2010). Acute bronchiolitis is defined as an acute inflammation of the bronchiolar airways, which may cause airway obstruction and respiratory distress via bronchiolar wall oedema, spasm and mucous production within the bronchiolar lumen (Sachdeva and Dutta, 2012). Several viruses can cause bronchiolitis.
Respiratory syncytial virus (RSV), parainfluenza viruses (PIV), influenza type A and adenovirus are some of the common viruses found in hospital studies (Debiaggi et al., 2012). Technological advances in the field of molecular biology have allowed virologists to detect many previously undetected viral pathogens (Hustedt and Vazquez, 2010), one of these pathogens was the human metapneumovirus (HMPV) which is a 
respiratory pathogen identified in The Netherlands in 2001, and was thought to cause upper and lower respiratory tract infections in children (Van den Hoogen et al., 2001).

It is an enveloped, non segmented, negativesense RNA virus classified in the subfamily Pneumovirinae of the family Paramyxoviridae (Falsey et al., 2003).

Indeed, HMPV appears to be an important global cause of clinical manifestations, including upper respiratory tract infections, bronchiolitis, and pneumonia in young children. Its epidemiology in Africa is poorly described and factors that allow its recurrent epidemics in communities are not understood (Williams et al., 2004; Owor et al., 2016).

The use of rapid tests for the diagnosis HMPV and other respiratory tract viral infections allows implementation of appropriate infection control measures, thus reducing nosocomial spread, and is useful for consideration of timely treatment with antiviral agents.

The clinical and financial benefits of the rapid detection of viruses in respiratory specimens have been demonstrated in several studies, indicating a direct correlation between a rapid turnaround time and decreased mortality, a decreased length of stay, overall costs, and better antibiotic stewardship (Macfarlane et al., 2005).

The aim of this study is the molecular diagnosis of HMPV infections by using a real-time, reverse-transcriptase PCR assay and the evaluation of its prevalence among Egyptian infants clinically diagnosed with acute viral bronchiolitis. We also aimed to detect other common respiratory viruses and determine the presence of coinfections of HMPV and other respiratory viruses.

\section{Materials and Methods}

\section{Subjects}

This study included 50 Egyptian infants attending the Alexandria University Pediatric Hospital (Alexandria, Egypt), and clinically diagnosed with acute viral bronchiolitis during the winter/spring season.

\section{Ethical considerations}

Under the guidelines of the committee of ethics of the medical research institute (MRI) of Alexandria University, an informed consent was obtained from the parents of each infant prior to sample collection.

\section{Clinical specimens}

Two samples were collected from each infant; the first was a nasopharyngeal aspirate collected by using sterile extractor and screened immediately. The second was a throat swab collected by using the standard plastic-shafted virocult ${ }^{\circledR}$ swabs, separated into aliquots and kept frozen at $-70^{\circ} \mathrm{C}$ for further PCR analysis.

\section{Immunofluorescence respiratory screen test}

Nasopharyngeal aspirates were diluted by 2 ml PBS and qualitatively screened for the presence of HMPV immediately after collection by using IMAGEN ${ }^{\mathrm{TM}}$ Respiratory Screen kit (Oxoid, Hampshire, UK) for the detection of RSV, influenza A and B viruses, Parainfluenza virus 1, 2 and 3 and adenovirus in respiratory specimens according to the manufacturer's instructions. This test contains a pool of monoclonal antibodies each of which has individual specificity for either of the above mentioned viruses. The pooled antibody screening reagent is used in a twostep indirect immunoflorescence staining technique (Parija, 2014). 


\section{RNA extraction}

Extraction of HMPV RNA was performed using the QIAmp® Viral RNA Mini-Kit (QIAGEN, HILDEN, Germany), according to the QIAmp® Viral RNA Mini spin procedure illustrated in the manufacturer's handbook. Before being processed for RNA extraction, samples were first brought at room temperature, centrifuged for 10 minutes at $15000 \mathrm{xg}$ and the supernatant was used for nucleic acid amplification Real time RT-PCR.

\section{Real-time RT-PCR for detection of HMPV}

Real-time RT-PCR assay was performed by using the PrimerDesign ${ }^{\mathrm{TM}}$ genesig qPCR Detection Kit (PrimerDesign, Southampton, UK) to molecularly detect HMPV in patients' nasopharyngeal specimens by targeting nucleoprotein gene. Detection was made by the Applied Biosystems StepOne ${ }^{\mathrm{TM}}$ RealTime PCR System (Applied Biosystems, Inc., Foster City, CA, United States).

\section{Statistical analysis}

Data were organized and processed by the Statistical Package for the Social Science (SPSS) program 22.0 (SPSS. Chicago,IL, USA), using the Chi square test at a $95 \%$ level of confidence. A p-value of $<0.05$ was considered statistically significant.

\section{Results and Discussion}

The age distribution among the 50 infants included in this study is shown in Figure 1. It was found that the peak age of infection was between 1 to three months, and the infections were more frequent in males $(72 \%$ of the cases). Samples from the 50 infant patients were collected during the winter/spring season over the period of 3 months as shown in Figure 2, most of the samples were collected in January (46\%) and this number decreases in the spring where only $14 \%$ of the cases were collected in March.

The clinical and radiological findings observed among the studied cases were shown in Figure 3 where coughing and wheezing were the most predominant findings observed in $98 \%$ and $96 \%$ of the cases, respectively.

\section{IMAGEN@ immunofluorescence respiratory screen test}

This test was used to qualitatively detect the viral antigens of any of the 7 most common respiratory viruses that could infect respiratory epithelia and cause lower respiratory tract infections in young children. In this study $38(76 \%)$ cases were positive either to one or more of those 7 mentioned viruses. The cells with positive results appeared with intracellular apple-green cytoplasmic and/or nuclear fluorescence contrasting against a background of red counterstained material. The negative results, on the other hand, showed cells with no intracellular apple-green fluorescence, only background red counter-staining was visible under fluorescence microscopy (Figure 4).

\section{Real-time RT PCR results for human metapneumovirus}

Eight cases (16\%) were found to be positive for HMPV nucleic acid by using the PrimerDesign $^{\mathrm{TM}}$ genesig qPCR Detection Kit.

It was noticed that 6 of the 8 positive cases for HMPV detected by PCR were also positive by immunoflorescence for at least one of the 7 respiratory viruses detected by the IMAGEN ${ }^{\circledR}$ respiratory screen kit (RSV, influenza $\mathrm{A} / \mathrm{B}$, parainfluenza types 1-3 and adenovirus). It was also found that $10(20 \%)$ of the studied cases were negative for all the tested viruses. 
Table.1 Collective results for both Immunofluorescence and PCR

\begin{tabular}{|c|c|c|c|c|c|c|c|}
\hline & \multicolumn{4}{|c|}{$\begin{array}{l}\text { Immunoflurescence for RSV, influenza } \\
\text { A/B, Parainfluenza 1-3 and Adenovirus }\end{array}$} & \multirow{2}{*}{\multicolumn{2}{|c|}{ Total }} \\
\hline & & \multicolumn{2}{|c|}{ Positive } & \multicolumn{2}{|c|}{ Negative } & & \\
\hline & & Number & $\%$ & Number & $\%$ & Number & $\%$ \\
\hline \multirow{2}{*}{$\begin{array}{l}\text { PCR } \\
\text { results } \\
\text { for } \\
\text { HMPV }\end{array}$} & Positive & 6 & 12 & 2 & 4 & 8 & 16 \\
\hline & Negative & 32 & 64 & 10 & 20 & 42 & 84 \\
\hline \multicolumn{2}{|l|}{ Total } & 38 & 76 & 12 & 24 & 50 & 100 \\
\hline
\end{tabular}

Table.2 Clinical findings in patients with respiratory viruses other than HMPV, patients with HMPV, and patients negative to any of the tested viruses in the study

\begin{tabular}{|c|c|c|c|c|c|c|c|c|}
\hline & \multicolumn{6}{|c|}{ Type of viral infection detected } & \multicolumn{2}{|c|}{ p-value } \\
\hline & \multicolumn{2}{|c|}{\begin{tabular}{l}
\multicolumn{2}{l}{ Respiratory } \\
viruses other \\
than HMPV* \\
$(n=32)$
\end{tabular}} & \multicolumn{2}{|c|}{$\begin{array}{l}\text { HPMV with or } \\
\text { without } \\
\text { coinfection }(n=8)\end{array}$} & \multicolumn{2}{|c|}{$\begin{array}{l}\text { Negative to tested } \\
\text { viruses }(n=10)\end{array}$} & \multirow[t]{2}{*}{$\mathrm{P} 1$} & \multirow[t]{2}{*}{$\mathrm{P} 2$} \\
\hline & Number & $\%$ & Number & $\%$ & number & $\%$ & & \\
\hline Cough & 32 & 100 & 8 & 100 & 9 & 90 & - & 1 \\
\hline Wheezing & 30 & 93.7 & 8 & 100 & 10 & 100 & 1 & - \\
\hline Fever & 20 & 62.5 & 8 & 100 & 8 & 80 & 0.079 & 0.477 \\
\hline $\begin{array}{l}\text { Feeding } \\
\text { difficulties }\end{array}$ & 18 & 56.2 & 6 & 75 & 3 & 30 & 0.439 & 0.153 \\
\hline Dyspnea & 9 & 28.1 & 0 & 0 & 0 & 0 & 0.162 & - \\
\hline Tachypnea & 19 & 59.3 & 5 & 62.5 & 7 & 70 & 0.72 & 1 \\
\hline Vomiting & 17 & 53.1 & 5 & 62.5 & 6 & 60 & 0.209 & 1 \\
\hline Rhinorrhea & 7 & 21.8 & 4 & 50 & 3 & 30 & 0.182 & 0.63 \\
\hline Hypoxemia & 6 & 18.7 & 2 & 25 & 0 & 0 & 0.65 & 0.183 \\
\hline Grunting & 1 & 3.1 & 2 & 25 & 3 & 30 & 0.096 & 1 \\
\hline Diarrhea & 1 & 3.1 & 1 & 12.5 & 1 & 10 & 0.356 & 1 \\
\hline Otitis media & 0 & 0 & 0 & 0 & 1 & 10 & - & 1 \\
\hline $\begin{array}{l}\text { Hyper- } \\
\text { inflated CXR }\end{array}$ & 31 & 96.8 & 7 & 87.5 & 9 & 90 & 0.364 & 1 \\
\hline \multicolumn{9}{|c|}{$\begin{array}{l}\text { * RSV and/or influenza A/B, parainfluenza types (1-3) or adenovirus } \\
\text { p1 compares HMPV- positive patients with patients positive to respiratory viruses other than } \\
\text { HMPV. } \\
\text { p2 compares HMPV- positive patients with patients negative to respiratory viruses in the } \\
\text { study. }\end{array}$} \\
\hline
\end{tabular}


Figure.1 Age and sex distribution among all the studied patients

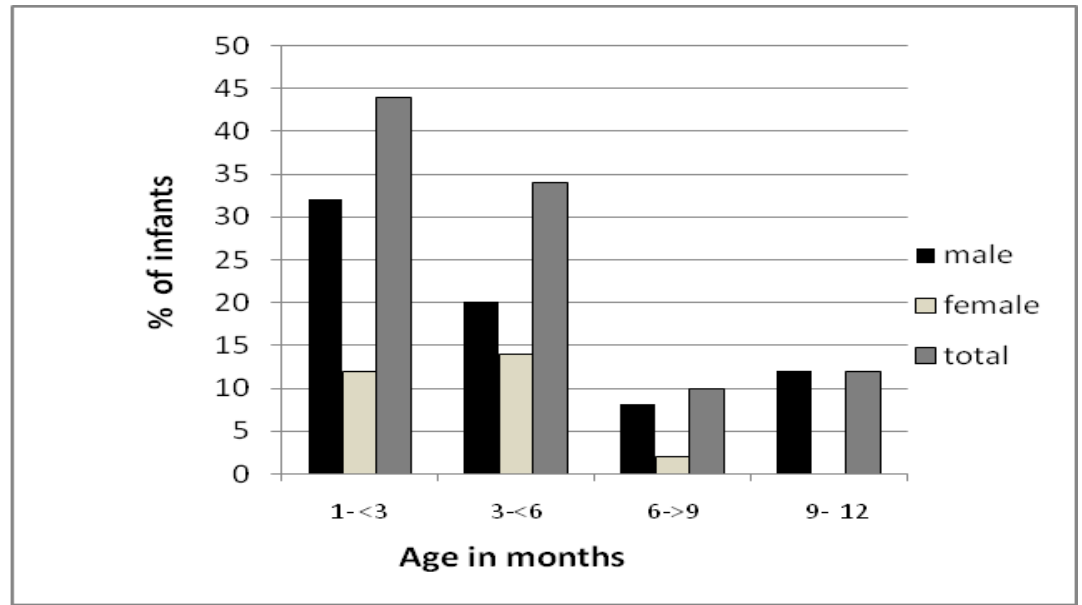

Figure.2 Seasonal distribution bronchiolitis in the studied patients

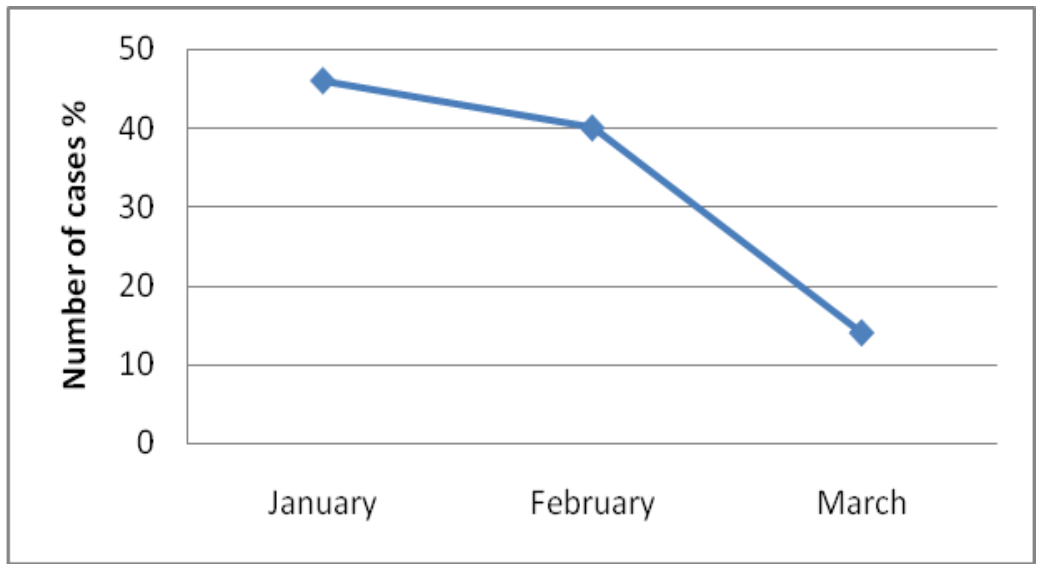

Figure. 3 The clinical and radiological findings observed among the studied patients

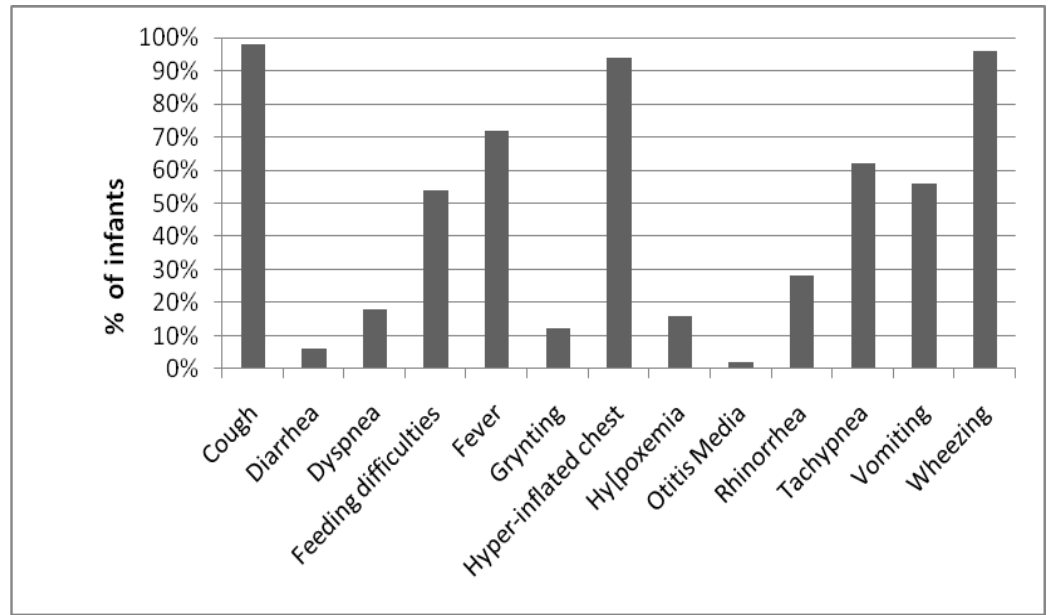


Figure.4 Shows (A) the clinically positive IMAGEM® immunofluorescence slide sample stained and prepared according to the instructions of the kit's manufacturer that appeared to have fluorescence patterns, and (B) A negative diagnosed sample that didn't exhibit this fluorescence

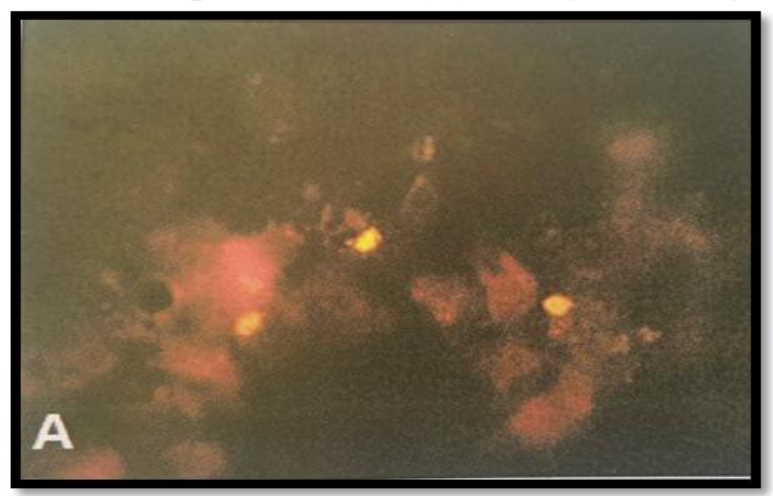

Viral respiratory infections continue to be a worldwide health concern. As the clinical symptoms of patients with acute respiratory tract infections do not usually allow a discrimination of viral or bacterial aetiology, rapid and reliable diagnostic tools are required for better antibiotic stewardship and for the implementation of appropriate infection control measures (Zaas et al., 2014)

According to the Official Journal of the American Academy of Pediatrics, more than one third of children develop bronchiolitis during the first two years of life (Ralston et al., 2014). Another study reported that in infants up to 3 months old, RSV was by far the most common pathogen $(58.1 \%)$ (Richter et al., 2016). In the present study all the tested patients were reported to be less than one year of age. The peak age of infection was found to be between one month and less than three months of age (44\%), whereas only $22 \%$ of the patients were in the age of 6 months or above (Figure 1). Similar to our findings, Bradley et al., suggested that young age is a significant risk factor for acute bronchiolitis in children (Bradley et al., 2005), also Owor et al., reported that $73 \%$ of the cases diagnosed with HMPV were less than one year of age (Owor et al., 2016). A study of risk factors associated with bronchiolitis in children less than 2 years of age reported that gender, unlike age, didn't show statistically significant association with bronchiolitis (Ruiz-Charles et al., 2001).

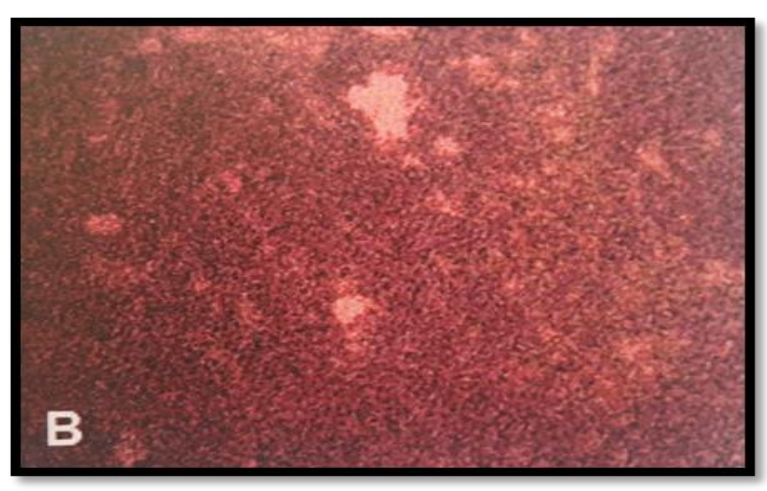

However, according to another study the male gender is associated with an increased risk of having a bronchiolitis episode and/ or longer duration (Flaherman et al., 2012). Similarly, in our study the majority of the studied patients (72\%) diagnosed with acute bronchiolitis were found to be males.

Bronchiolitis is a seasonal illness having peak prevalence in winter months and early spring (November to March), when such infectious viruses are widespread in the community (Baumer, 2007). In our study, 46\%, 40\%, and $14 \%$ of the cases were found in January, February and March respectively. Similarly Owor et al., found that the cases were predominant in the months of November through April (Owor et al., 2016). In other parts of the world, seasonality in HMPV prevalence has been previously reported (Bastien et al., 2003; Mullins, 2004; Ahmed et al., 2012).

In the present study, a qualitative indirect imminofluorescence screening assay was used to test the presence of seven common respiratory viruses other than HMPV (RSV, influenza virus $A$ and $B$, parainfluenza virus types 1-3 and adenovirus). Seventy six $\%$ of the cases were reported to be positive to at least one or more of these viruses. Another screening study also made by using antigen specific immunofluorescence assay (IMAGEN® respiratory screening test) reported that $60.6 \%$ of the tested samples were positive to any of the 
respiratory tract viruses (Kleines et al., 2007). The HMPV was detected in $16 \%$ of our studies cases. Similarly, Owor et al., showed that this virus was detected in $4.8 \%$ of the cases clinically diagnosed with pneumonia (Owor et al., 2016). Other studies also reported that HMPV has been estimated to account for 3\% to19\% of bronchiolitis cases (Xepapadaki et al., 2004; Kahn, 2006).

We also studied the clinical impact of HMPV coinfection with other common respiratory tract viruses, and we found that $6(12 \%)$ of the 8 $(16 \%)$ cases that were found to be positive for HMPV were also positive for at least one of the other seven studied respiratory viruses. In a another study, mixed infections were observed in approximately $20 \%$ of all the tested samples (Richter et al., 2016). It has been shown that viral coinfection was significantly associated with longer duration of illness symptoms, also severe clinical phenotypes were more prevalent in coinfection patients, especially in RSV, this may increase the severity of RSV associated disease in children (Cho et al., 2013; Wu et al., 2015).

In conclusion the present study revealed that HMPV is an important seasonal contributor to respiratory diseases in Egyptian infants and it is a common cause of acute bronchiolitis that should be considered in etiological diagnosis. It could be found as the sole pathogen or may be present associated with other common respiratory viruses. Future advances in the molecular and diagnostic techniques would help in identifying newly emerging respiratory viruses that were unidentified previously.

\section{References}

Ahmed, J.A., Katz, M.A., Auko, E., Njenga, M.K., Weinberg, M., Kapella, B.K., Burke, H., Nyoka, R., Gichangi, A., Waiboci, L.W. 2012. Epidemiology of respiratory viral infections in two long-term refugee camps in Kenya, 2007-2010. BMC Infect. Dis., 12: 7.
Bastien, N., Ward, D., Van Caeseele, P., Brandt, K., Lee, S.H., McNabb, G., Klisko, B., Chan, E., Li, Y. 2003. Human metapneumovirus infection in the Canadian population. J. Clin. Microbiol., 41: 46424646.

Baumer, J.H. 2007. SIGN guideline on bronchiolitis in infants. Archives of disease in childhood-Education and practice edition. 92:ep149-ep151.

Bradley, J.P., Bacharier, L.B., Bonfiglio, J., Schechtman, K.B., Strunk, R., Storch, G., Castro, M. 2005. Severity of respiratory syncytial virus bronchiolitis is affected by cigarette smoke exposure and atopy. Pediatrics, 115: e7-e14.

Cho, H.J., Shim, S.Y., Son, D.W., Sun, Y.H., Tchah, H., Jeon, I.S. 2013. Respiratory viruses in neonates hospitalized with acute lower respiratory tract infections. Pediatrics Int., 55: 49-53.

Debiaggi, M., Canducci, F., Ceresola, E.R., Clementi, M. 2012. The role of infections and coinfections with newly identified and emerging respiratory viruses in children. Virol. J., 9: 247.

Falsey, A.R., Erdman, D., Anderson, L.J., Walsh, E.E. 2003. Human metapneumovirus infections in young and elderly adults. $J$. Infect. Dis., 187: 785-790.

Flaherman, V.J., Ragins, A.I., Li, S.X., Kipnis, P., Masaquel, A., Escobar, G.J. 2012. Frequency, duration and predictors of bronchiolitis episodes of care among infants $\geq 32$ weeks gestation in a large integrated healthcare system: a retrospective cohort study. BMC Health Services Res., 12: 144.

Hustedt, J.W., Vazquez, M. 2010. The changing face of pediatric respiratory tract infections: how human metapneumovirus and human bocavirus fit into the overall etiology of respiratory tract infections in young children. The Yale J. Biol. Med., 83: 193200.

Kahn, J.S. 2006. Epidemiology of human metapneumovirus. Clin. Microbiol. Rev., 19: 546-557.

Kleines, M., Scheithauer, S., Rackowitz, A., Ritter, K., Häusler, M. 2007. High prevalence of human bocavirus detected in 
young children with severe acute lower respiratory tract disease by use of a standard PCR protocol and a novel realtime PCR protocol. J. Clin. Microbiol., 45: 1032-1034.

Macfarlane, P., Denham, J., Assous, J., Hughes, C. 2005. RSV testing in bronchiolitis: which nasal sampling method is best? Archives of disease in childhood, 90: 634635.

Mullins, J.A. 2004. Human Metapneumovirus Infection among Children Hospitalized with Acute Respiratory Illness-Volume 10, Number 4-April 2004-Emerging Infect. Dis. J., CDC.

Owor, B.E., Masankwa, G.N., Mwango, L.C., Njeru, R.W., Agoti, C.N., Nokes, D.J. 2016. Human metapneumovirus epidemiological and evolutionary patterns in Coastal Kenya, 2007-11. BMC Infect. Dis., 16: 301.

Parija, S.C. 2014. Textbook of microbiology and immunology. Elsevier Health Sciences.

Ralston, S., Lieberthal, A., Meissner, H. 2014. American Academy of Pediatrics Subcommittee on Diagnosis and Management of Bronchiolitis. Clinical practice guideline: the diagnosis, management, and prevention of bronchiolitis. Pediatrics, 134: e1474-e1502.

Richter, J., Panayiotou, C., Tryfonos, C., Koptides, D., Koliou, M., Kalogirou, N., Georgiou, E., Christodoulou, C. 2016. Aetiology of Acute Respiratory Tract Infections in Hospitalised Children in Cyprus. PloS one, 11: e 0147041.

Ruiz-Charles, M.G., Castillo-Rendón, R., Bermúdez-Felizardo, F. 2001. Risk factors associated with bronchiolitis in children under 2 years of age. Revista de investigacion clinica; organo del Hospital de Enfermedades de la Nutricion, 54: 125132.

Sachdeva, A., Dutta, A., 2012. Adv. Pediatrics, JP Medical Ltd.

Van den Hoogen, B.G., de Jong, J.C., Groen, J., Kuiken, T., de Groot, R., Fouchier, R.A., Osterhaus, A.D. 2001. A newly discovered human pneumovirus isolated from young children with respiratory tract disease. Nature Med., 7: 719-724.

Williams, J.V., Harris, P.A., Tollefson, S.J., Halburnt-Rush, L.L., Pingsterhaus, J.M., Edwards, K.M., Wright, P.F., Crowe Jr, J.E. 2004. Human metapneumovirus and lower respiratory tract disease in otherwise healthy infants and children. New England J. Med., 350: 443-450.

Wu, X., Wang, Q., Wang, M., Su, X., Xing, Z., Zhang, W., Shi, Y. 2015. Incidence of respiratory viral infections detected by PCR and real-time PCR in adult patients with community-acquired pneumonia: a metaanalysis. Respir., 89: 343-352.

Xepapadaki, P., Psarras, S., Bossios, A., Tsolia, M., Gourgiotis, D., Liapi-Adamidou, G., Constantopoulos, A.G., Kafetzis, D., Papadopoulos, N.G. 2004. Human metapneumovirus as a causative agent of acute bronchiolitis in infants. J. Clin. Virol., 30: 267-270.

Zaas, A.K., Garner, B.H., Tsalik, E.L., Burke, T., Woods, C.W., Ginsburg, G.S. 2014. The current epidemiology and clinical decisions surrounding acute respiratory infections. Trends in Mol. Med., 20: 579-588.

\section{How to cite this article:}

Gamal El-Din El-Sawaf, Maged Eissa, Abeer Ghazal, Dalia Metwally, Rania Abozahra and Walid Rafla. 2017. Molecular Diagnosis of Human Metapneumovirus Infection Among Egyptian Infants With Acute Bronchiolitis. Int.J.Curr.Microbiol.App.Sci. 6(3): 2430-2437. doi: https://doi.org/10.20546/ijcmas.2017.603.277 